\title{
DE LA GÉNESIS DE LA PSICOLOGÍA MODERNA Y DEL DESCONOCIMIENTO DE KIERKEGAARD EN LA HISTORIA DE LA PSICOLOGÍA http://doi.org/10.54354/SUIW9312
}

\author{
Edgar Bennetts \\ Universidad Nacional Autónoma de México
}

\section{Resumen}

La psicología moderna ya tiene más de cien años desde su origen; hasta el día de hoy, no hay un acuerdo unánime y absoluto sobre qué es la mente humana o cómo interpretar un fenómeno conductual. No hay una teoría que dé cuenta de la psique humana, hay muchas. En este sentido, la interpretación de la conducta no es exclusiva de la psicología, le antecede -por lo menos- la filosofía occidental. Este artículo, pretende dar claves muy generales y escuetas de cómo se construye la idea de la psicología moderna y cómo construye ésta, su historia. Se sostiene en consecuencia que, en términos generales, la historia de la psicología "canónica" (anglosajona y relacionada con la APA) desconoce la filosofía de Kierkegaard y a éste, como un pensador relevante de la psique humana dentro de la historia general de la psicología. En un último apartado se expondrá la relevancia y lugar que, a consideración de este texto, tiene Kierkegaard en la historia de la psicología.

Palabras clave: Psicología moderna, historia de la psicología, Kierkegaard, repetición, desesperación.

\begin{abstract}
Modern psychology is more than a hundred years old since its origin; to this day, there is no unanimous and absolute agreement on what the human mind is or how to interpret a behavioral phenomenon. There is no theory that accounts for the human psyche, there are many. In this sense, the interpretation of behavior is not exclusive to psychology, it precedes -at least- western philosophy. This article tries to give keys to how the idea of modern psychology is constructed and how it constructs its history. Consequently, it is argued that, in general terms, the history of "canonical" psychology (Anglo-Saxon and related to the APA) does not know Kierkegaard's philosophy nor him, as a relevant thinker of the
\end{abstract}

Recibido el 15 de mayo de 2021; aceptado el 3 de junio de 2021. 
human psyche within the general history of psychology. In a last section, the relevance and place that Kierkegaard has in the history of psychology will be discussed.

Keywords: Modern psychology, history of psychology, Kierkegaard, re-petition, desperation.

\section{Introducción}

La palabra «psicología» como bien puede saberse, tiene sus orígenes en el mundo griego. Podemos encontrar una psicología en Platón, Aristóteles, San Agustín, Tomás de Aquino, etc. Ya en la modernidad, surge una confluencia de diferentes campos de estudio que van a alterar la concepción de psicología que se tenía hasta el momento. La fisiología, la medicina, la ciencia moderna en general van a ser factores que modifiquen a la ciencia del alma. De manera sustancial, en el centro del debate sobre la psique humana entre la fisiología y la religión, por ejemplo, estuvo la filosofía, la cual, a su vez, afectó el devenir de la psicología moderna. Desde el racionalismo hasta el romanticismo, la filosofía se situó en el debate del comportamiento y su explicación última. Lo curioso del caso es cómo terminaron excluidas o poco reconocidas ciertas teorías filosóficas del comportamiento.

Entre los siglos XVII y XIX, el debate sobre la naturaleza de la mente, sus modos, sus alcances, sus principios y demás, es realmente un debate denso, en cual compartieron ideas algunos de los más destacados pensadores; se dieron varios intercambios intelectuales con respecto a la naturaleza del alma humana y su derivada conducta. Muchos a favor de una teoría trascendental, otros a favor de una teoría vitalista, todos sumergidos en un profundo debate que diera razón del por qué el ser humano actuaba de cierta manera. Ya en el siglo XIX, en el centro de la densidad intelectual de la época, surge la psicología moderna como ciencia empírica, tratando de dar un respiro al denso debate intelectual (como una especie de culminación de dicho debate alimentado por el positivismo). Surge esta ciencia pues, como resultado del desarrollo histórico del movimiento moderno que pretende el uso del método científico; se considera que la historia universal va avanzando hacia un ineludible progreso humano, la psicología no es la excepción.

En los bordes del surgimiento de la psicología moderna, hay evidentemente partidarios de ésta, que consideran necesario el uso del 
método científico, así como de la medición del comportamiento en términos numéricos: Ebbinghaus, Fechner, Wundt. Por otra parte, W. Dilthey centró mucho de su trabajo en expresar la irreductibilidad de las ciencias del espíritu a las ciencias naturales. Expresó fehacientemente el error de generar una ciencia psicológica apoyada en el método científico ${ }^{1}$. Otros como Brentano notaron la importancia que tenía la intencionalidad de la consciencia en los actos humanos, por lo que dedicó mucho de su trabajo a fundamentar una psicología intencional o del acto ${ }^{2}$. En síntesis, las posturas que discutieron la fundamentación de la psicología (Ebbinghaus y Dilthey, por ejemplo), son al final de cuentas posturas que la historia de la psicología reconoce como antecedentes de ésta, pero ¿Kierkegaard o Nietzsche no aportaron nada al debate del alma y su respectivo funcionamiento? Ya se verá que para la historia canónica de la psicología estos autores al parecer no aportaron nada, o al menos, se desconoce en general cuál fue en específico su aporte.

\section{Génesis de la psicología moderna}

En general, el concepto de psicología refiere a un campo de conocimiento o a una ciencia que se encarga del estudio, análisis e interpretación de la conducta y los procesos mentales, ya sea de manera particular (de individuos o sujetos) o de manera general (psicología de las masas o social). Así bien, la psicología como ciencia moderna, parte de la premisa de que los fenómenos observables de la conducta pueden ser objetivamente medibles y estandarizables. Es en este aspecto que se habla de la separación de la psicología con respecto a la filosofía, en el sentido de un profundo cambio epistémico y metodológico. La psicología se desprende de la filosofía por la incorporación del método científico, mientras que la filosofía se queda como la gran investigación abstracta y conceptual de la realidad, ya sea ésta: analítica, sintética, fenomenológica, etc. Entonces, la psicología es una ciencia o saber que se enmarca y diferencia de otras ciencias por su análisis y método; la psicología no es filosofía, ni sociología, ni antropología, ni religión. De esta manera, hoy por psicología se entiende un especifico tipo

1 Cfr. Wilhem Dilthey, Introducción a las ciencias del espiritu, trad. de Eugenio Imaz, México: F.C.E., 1978.

2 Cfr. Franz Brentano, Psychology from an Empirical Standpoint, London: Routledge, 1995 y María Chirinos, Intencionalidad y verdad en el juicio. Una propuesta de Brentano, Pamplona: EUNSA, 1994. 
de análisis y resultado, que varía enormemente según la tradición o escuela de la que se parta, llámese conductismo o humanista.

En efecto, la psicología reconoce sus inicios modernos con W. Wundt debido a que éste fue el que formalmente fundó el primer laboratorio de psicología experimental (1879). Así, se construye la idea de lo que es la psicología moderna, entendiendo por ésta, aquella que se aleja de la filosofía especulativa y de las explicaciones religiosas acerca de la conducta de los individuos. La psicología moderna va a desechar, por ejemplo, la explicación religiosa y va a referir que la conducta "anormal" se puede explicar desde otras vías: como el mal funcionamiento nervioso o cerebral (Gall, Pinel, Charcot, entre otros). Distintivamente la psicología moderna sostendrá que las conductas anormales o patológicas tienen una explicación racional, no mítica o fantástica como lo llegó a sostener la religión católica en la Edad Media.

En consecuencia, la psicología moderna va a sostener que el fenómeno conductual puede ser visto como externo de la consciencia del sujeto que lo observa, es decir, que el fenómeno conductual puede ser visto como un objeto de estudio. En este sentido, la propia conducta del sujeto que analiza puede ser analizada de manera objetiva y externa a él, lo que permitiría un estudio general de la conducta humana. Además, la psicología moderna sostiene que el alma humana se correlaciona con el funcionamiento y estructura del cuerpo, es decir, que de ciertos fenómenos fisiológicos derivan ciertas formas de comportamiento, hay pues una correlación entre cuerpo y alma, y no sólo el alma de manera puramente metafísica. Aquí, evidentemente se puede apreciar la influencia de la fisiología o la medicina moderna; en este postulado, ya se vería un cierto alejamiento con relación a la filosofía especulativa. En consecuencia, la psicología moderna se aleja de su antecesora, la psicología metafísica. Otro postulado de la psicología moderna sería que además de que el fenómeno conductual se puede analizar como un objeto externo a la consciencia, éste se puede medir, estandarizar y universalizar, es decir, que un comportamiento tal, analizado y repetido varias veces, al ser éste así, es igualmente válido para todos los seres humanos ${ }^{3}$.

En general, por psicología moderna se entiende lo que ya se ha dicho en los párrafos anteriores, algunos de sus postulados son los que se refirieron, y su origen lo podemos situar en el siglo XIX con las investigaciones de

3 Aquí se sitúa de lleno la crítica de Dilthey, pues éste consideraba improcedente la reproductibilidad del fenómeno conductual, así como la captación fenoménica de los estados de ánimo. Véase Dilthey, Introducción a las ciencias del espíritu, pp. 70-73. 
Wilhelm Wundt. A esto, hay que agregarle que la psicología moderna tuvo serias influencias de diferentes partes, por ejemplo, no podríamos hablar de psicología moderna, sin hablar del padre de la filosofía moderna: René Descartes. La influencia de éste es enorme, pero también lo es de otros filósofos como Locke, Hume o Kant. Otras influencias vinieron directamente de los avances de la fisiología, en específico, de Franz Joseph Gall, Charles Bells, Hermann von Helmholtz, entre otros. A su vez, surge el movimiento llamado «psicofísica» que también tuvo influencias en el desarrollo de la psicología moderna. La frenología, el evolucionismo darwiniano y otros saberes, también confluyen en el desarrollo de ésta. Evidentemente, la psicología moderna surge como consecuencia de la modernidad y se compenetra en ésta: en sus grandes postulados, finalidades y métodos. Imposible ver el surgimiento de la psicología moderna sin el movimiento moderno. $\mathrm{Y}$ esto es muy importante para entender por qué se excluye a Kierkegaard y otros pensadores de la psique humana de la canónica historia de la psicología.

\section{Historia de la psicología: una bistoria a favor de la modernidad, la ciencia y la racionalidad en Occidente}

La historia de la psicología se escribe partiendo del concepto moderno de psicología, no del concepto o término general de psicología ( $\left.\psi v \chi \eta^{\prime} \lambda \circ \gamma^{\prime} \alpha\right)$, que ha estado bien presente desde el inicio de la filosofía occidental y en otras formas de pensamiento no occidentales. Se busca en el pasado los orígenes o antecedentes de la psicología y se comienza partiendo de los textos oficiales y canónicos de historia "universal". Buscan su origen antiguo y, en consecuencia, lo van a encontrar en los griegos, pero no en todo el mundo griego, sino en los buenos del cuento: Sócrates, Platón, Aristóteles. Ni siquiera existe la cuestión de buscar un posible origen de la psicología en las culturas no occidentales, o sea, ¿puede haber un pensamiento psicológico o psicoterapéutico en el budismo o en las filosofías de la India como lo es el vedānta o el tantra? ${ }^{4}$ Tampoco hay una búsqueda

4 Sucede un fenómeno interesante en India. Lo que a nosotros ha llegado como "hinduismo", desde el siglo XIX hasta hace poco, en realidad es una reinterpretación y estandarización de la historia de la India. Sarvepalli Radhakrishnan escribe su Historia de la filosofía de la India teniendo en cuenta su tradición religiosa: el vedānta. Por esta razón, aunado a su posición política y pretensión de dotar a la India de una identidad nacional, selecciona e interpreta intencionalmente todas aquellas filosofías que no embonan directamente con el canon védico: cārvākas, àjīvikas, jainistas, budistas, etc. Por lo tanto, la 
de los orígenes de la psicología en los malos de cuento, o sea, los sofistas, los cínicos, los cirenaicos, los epicúreos... Se sabe de la existencia de estas escuelas, pero como va a pasar con Kierkegaard, no se les otorga el valor y relevancia que tienen en la historia general de la psicología.

La pregunta importante es ¿por qué no se les otorga relevancia a estas escuelas en cuanto al pensamiento psicológico? ¿Es acaso que, en efecto, no tienen ninguna relevancia para ser mencionadas en la historia general de la psicología? ¿Acaso el origen del término «terapia psicológica» ( $\theta \varepsilon p \alpha \pi \varepsilon i \alpha)$ es irrelevante para la historia de la psicología considerando que el primero en utilizarlo sistemáticamente fue Epicuro? ¿Por qué son tan escasos los textos de historia de la psicología que aborden a las filosofías helenísticas (entre ellas el epicureísmo) como algo relevante para la psicología, considerando que éstas son en sí, terapias del deseo?5 Michel Onfray menciona en su Contrabistoria de la filosofía, que los sofistas pudieron haber sido algunos de los primeros terapeutas del mundo occidental, y que, Antifón de Atenas es, por medio de diferentes técnicas y teorizaciones, el inventor de la psicoterapia y un precursor directo del psicoanálisis ${ }^{6}$. ¿Será como dice Onfray que no se ha hecho justicia a los sofistas por la enorme aversión de Platón a éstos? En el mismo sentido, ¿por qué ningún texto de historia de la psicología, traducido o escrito en español, menciona siquiera a Kierkegaard? ¿Acaso Kierkegaard no tiene relevancia en la historia del pensamiento psicológico? ¿No tuvo éste alguna forma interesante de pensar la conducta de los seres humanos? $¿$ ¿No dedica Kierkegaard un texto entero al concepto de repetición el cual explica directamente razones del comportamiento humano? ¿Qué hay de los trabajos de Kierkegaard La enfermedad mortal y El concepto de angustia? ¿No son estos trabajos donde se ve un empeño por demostrar el origen y posible solución de los tormentos del alma? ¿Acaso su pensamiento es irrelevante o menor en función de otros pensadores como Freud o William James? ¿Las teorías psicoanalíticas o conductistas subsumen del todo el

exclusión de doctrinas, ya sean filosóficas o psicológicas, no es un fenómeno exclusivo de Occidente; aunque nunca quedará claro si fue el afán occidental de unificar y organizar en un mismo discurso, lo que afectó, al final de cuentas, a que la India generará (influenciada por Occidente) este fenómeno de exclusión canónica en los tiempos de la conquista inglesa en la India. Cfr. Wilhelm Halbfass, India y Europa. Ejercicio de entendimiento filosófico, trad. de Óscar Figueroa, México: F.C.E., 2013, pp. 281-295.

5 Cfr. Martha Nussbaum, Terapia del deseo, trad. de Miguel Candel, Buenos Aires: Paidós, 2005.

6 Michel Onfray, Las sabidurías de la antigüedad: Contrabistoria de la filosofía I, trad. de Marco Aurelio Galmarini, Barcelona: Anagrama, 2008, p. 95. 
pensamiento de Kierkegaard para que éste sea interpretado como irrelevante en la historia de la psicología anglosajona?

Vayamos a los textos. Primero, existe un monopolio mundial de la historia de la psicología controlado por la tradición anglosajona y sus grandes editoriales, por ejemplo, la APA tiene el texto A Century of Psychology as Science ${ }^{7}$, que aborda la temática desde el inicio de la psicología moderna hasta nuestros tiempos; como era de esperarse, ni siquiera se menciona a Kierkegaard. McGraw Hill tiene tres importantes ediciones de historia de la psicología, muy vendidas y comercializadas. Hoterstall, Greenwoood y Tortosa son los autores de estas ediciones, y en ninguno se menciona si quiera a Kierkegaard ${ }^{8}$. Pearson, tiene otras dos de las ediciones más vendidas y difundidas; en ninguna de las dos se menciona a Kierkegaard? Estas ediciones que he comentado son probablemente las más leídas en el mundo de la historia de la psicología. Le siguen otras ediciones como la del F.C.E. (México), la edición de Ariel, Grijalbo, Paidós y Síntesis ${ }^{10}$; a su vez, le siguen otras ediciones hechas por universidades: UNAM, UAM, Cambridge, $\mathrm{Oxford}^{11}$. Curioso el caso: de todas las anteriores, ninguna le dedica un espacio a la figura de Kierkegaard. De todas las ediciones que he

7 Sigmund Koch, \& David Leary, (ed.) A Century of Psychology as Science, Washington: APA, 2002.

8 John Greenwood, Historia de la psicología: un enfoque conceptual, México: McGraw Hill, 2011, David Hothersall, Historia de la psicología, México: McGraw Hill, 1997 y Francisco Tortosa \& Cristina Civera, Historia de la psicología, México: McGraw Hill, 2006.

9 Thomas Hardy Leahey, Historia de la psicología, trad. de María de Ancos Rivera, Madrid: Pearson, 2005 y James Brennan, Historia y sistemas de la psicología, trad. de José Francisco Dávila Martínez, México: Pearson, 1999.

10 Como se ha venido mencionado, la historia general de la psicología excluye a Kierkegaard de ésta. En un primer momento, se mencionó la tradición anglosajona, pero la exclusión mencionada, no se remite sólo a ésta. Las diferentes editoriales mencionadas no se suscriben como tal, a la política editorial anglosajona, aun así, reflejan la misma línea de investigación y, por ende, la misma exclusión histórica. Por ejemplo, la edición de Grijalbo, con el título Historia crítica de la psicología, aunque sí aporta un análisis crítico de la historia de la psicología, en realidad no llega a la crítica que se esboza aquí, es decir, aunque dicha edición revisa la historia de manera diferente, en ella no se menciona siquiera a Kierkegaard.

11 Lo mismo que se ha planteado con todas las ediciones revisadas, pasa con las ediciones universitarias. Hasta donde ha llegado mi investigación, no he encontrado un sólo texto de historia de la psicología donde se dedique un apartado a la figura de Kierkegaard. Sólo encontré un texto, que no es como tal una historia de la psicología donde sí se trabaje el origen y desarrollo de ésta. Samuel Smith, Ideas of the Great Psychologists, New York: Barnes \& Noble, 1983. 
mencionado, sólo algunas exponen al romanticismo como algo relevante en la historia de la psicología, sólo una, menciona al irracionalismo como movimiento resaltante, y dos de ellas, mencionan al existencialismo como algo que aportó a la psicología humanista. ¡Ninguna menciona a Kierkegaard!12

En términos generales, el concepto de psicología que se discute en el siglo XIX, entre el idealismo, el romanticismo, el irracionalismo, la psicofísica, el intencionalismo, el marxismo, etc., es sin duda algo relevante en la historia de la psicología. La pregunta importante es ¿por qué quedaron fuera literalmente- de la historia de la psicología personajes como Kierkegaard, Nietzsche o Bergson? ¿Por qué ni siquiera se les menciona o se les menciona muy poco? ¿Acaso la psicología quiso emanciparse de manera abrupta de la filosofía que en ello sacrificó a algunos de los sus más destacados pensadores? ¿No era Nietzsche el que literalmente se autodenominaba psicólogo? Hasta ahora, mi investigación no ha llegado a una respuesta final, pero lo que he llegado a considerar es que la psicología moderna, al ser precisamente una concepción moderna, excluye en automático todo aquello que no es moderno como tal en su historia: el caso peculiar de Kierkegaard.

Ahora bien, fuera de la historia de la psicología, sí hay un reconocimiento de Kierkegaard como alguien relevante en el pensamiento e interpretación del comportamiento. Por ejemplo, toda la psicoterapia existencial reconoce y toma de Kierkegaard los conceptos de existencia, angustia y desesperación. De hecho, el texto de Rollo May, Existence: A New Dimension in Psychiatry and Psychology ${ }^{13}$, que fue uno de los primeros e influyentes textos de la psicoterapia existencial, menciona la deuda con Kierkegaard y los existencialistas. El texto argumenta que la dimensión de la existencia, como malestar y angustia ontológica, no ha estado presente en toda la historia de la psicología. De manera paralela, la psicología humanista también reconoce la relevancia e influencia de Kierkegaard en su teoría ${ }^{14}$. El propio Lacan, a lo largo de su enseñanza, menciona la relevancia del concepto kierkegaardiano de repetición; lo considera imprescindible para

12 Aunque mencionan al existencialismo, no dedican un apartado exclusivo para exponer la relevancia y teoría de Kierkegaard en la psicología. Hablan del existencialismo de Heidegger, Sartre, Marcel, pero ninguno habla de Kierkegaard.

13 Rollo May, Ernest Angel, y Henri Ellenberger, Existence: A New Dimension in Psychiatry and Psychology, Nueva York: Basic Books, 1958. En general, la psicoterapia existencial, incluyendo a Yalom, mencionan o le dedican un espacio a la figura de Kierkegaard. Cfr. Irving Yalom, Psicoterapia existencial, Barcelona: Herder, 2010.

14 Cfr. Manuel Villegas, Psicología bumanista: historia, concepto y método, Barcelona: Universidad de Barcelona, 1986 y José Luis Martorell \& José Prieto, Fundamentos de psicología, Madrid: C. A. Ramón Areces, 2008. 
entender los fenómenos de la psique en general y la clínica psicoanalítica ${ }^{15}$. Hasta donde sé, Freud nunca citó a Kierkegaard y nunca leyó al pensador danés; ya será Lacan, el que muestre el parentesco entre estos dos autores. Lacan, fuera de la historia de la psicología, sí reconoce el enorme aporte de Kierkegaard en la interpretación de la subjetividad y del comportamiento; el reconocimiento que hace Lacan a Kierkegaard no es menor, pues a lo largo de los textos se leen varias referencias a él.

\section{El espacio y lugar que merece Kierkegaard en la bistoria de la psicología}

Kierkegaard fue un pensador creativo y potente del alma humana, sus ideas se centraron en muchos sentidos, en dar una explicación del comportamiento humano y en dar una noción clara de lo que la existencia representaba para el hombre ${ }^{16}$. En este apartado, me centraré en explicar sólo algunos de los más relevantes aportes de Kierkegaard a la psicología, que, como se ha venido argumentando, se consideran excluidos de la canónica historia de la psicología. Si bien Kierkegaard no tuvo acceso a otros autores como Wundt y Freud, su pensamiento definitivamente aportó algo nuevo al tema del alma y el comportamiento.

15 En el Seminario XI, Lacan menciona: "Como todo nos lo indica en los hechos, la experiencia, la clínica, la repetición se funda en un retorno del goce. Y lo que el propio Freud articula en este sentido es que, en esta misma repetición, se produce algo que es un defecto, un fracaso. En su momento apunté aquí el parentesco que eso tiene con los enunciados de Kierkegaard". También en el Seminario sobre La carta robada, Lacan explica: "Así se sitúa Freud desde el principio en la oposición, sobre la que nos ha instruido Kierkegaard, referente a la noción de la existencia según se funde en la reminiscencia o en la repetición". Ver Jacques Lacan, Seminario XI. Los cuatro conceptos fundamentales del psicoanálisis, trad. de Rithee Cevasco y Vicente Mira Pascual, Buenos Aires: Paidós, 1993, p.42 y Jacques Lacan, "El seminario de la carta robada", trad. de Tomás Segovia, en Escritos I, México: Siglo XXI, 1984, p. 39-40.

${ }_{16} \mathrm{Al}$ parecer el padre de Kierkegaard desde muy temprana edad invitaba a éste, a hacer deducciones de la causa y sentido del comportamiento de las personas en general. Esta inclinación de Kierkegaard hacia la interpretación de la conducta va a estar presente a lo largo de toda su vida. Véase Søren Kierkegaard, Johannes Climacus o el dudar de todas las cosas, trad. de Patricia Carina Dip, Buenos Aires: Gorla, 2007, pp. 8-11. En sus Diarios, también puede apreciarse esta motivación a la interpretación de la conducta. Cfr. Søren Kierkegaard, Los primeros diarios. 1834-1835. Vol. I, trad. de María José Binetti Milanesi, México: Universidad Iberoamericana, 2011. 


\section{A. La repetición}

En el texto La repetición con el seudónimo de Constantin Constantius, Kierkegaard expone un análisis riguroso sobre las condiciones de posibilidad y del deseo humano de repetir acontecimientos del pasado. En este texto, Kierkegaard explora reflexivamente su vida y los límites de la existencia humana, cuestionando la posibilidad de la repetición, en lo que encuentra una única posibilidad de repetición: "que la repetición es imposible"17. Lo único que se repite es que la repetición es imposible. Así, el ser humano está subsumido en una dinámica que Kierkegaard nos presenta de la siguiente manera:

Lo peculiar del amor-repetición es la deliciosa seguridad del instante. La esperanza es un vestido nuevo, flamante, sin ningún pliegue ni arruga, pero del que no puedes saber, ya que no te lo has puesto nunca, si te cae o sienta bien. El recuerdo es un vestido desechado que, por muy bello que sea o te parezca, no te puede caer bien, pues ya no corresponde a tu estatura. La repetición es un vestido indestructible que se acomoda perfecta y delicadamente a tu talle, sin presionarte lo más mínimo y sin que, por otra parte, parezca que llevas encima como un saco. La esperanza es una encantadora muchacha que, irremisiblemente, se le escurre a uno entre las manos. El recuerdo es una vieja mujer todavía hermosa, pero con la que ya no puedes intentar nada en el instante. La repetición es una esposa amada, de la que nunca jamás llegas a sentir hastío, porque solamente se cansa uno de lo nuevo, pero no de las cosas antiguas, cuya presencia constituye una fuente inagotable de placer y felicidad. Claro que, para ser verdaderamente feliz en este último caso, es necesario no dejarse engañar con la idea fantástica de que la repetición tiene que ofrecerle a uno algo nuevo, pues entonces le causará hastío ${ }^{18}$.

Con respecto a esta idea kierkegaardiana de la repetición, encontramos a un sujeto que tiende a repetir eventos de su vida dada cierta experiencia fijada en la memoria. Se pretende repetir por el recuerdo que se tiene del acontecimiento pasado en relación con la esperanza, la cual aporta el elemento de incertidumbre de que dicho nuevo evento reviva ese evento del pasado. Kierkegaard se pregunta ¿será posible la repetición?, en el sentido de que la psique humana pueda satisfacerse plenamente con volver hacer esas cosas que lo marcaron. La conclusión de Kierkegaard al respecto es que, en efecto, la repetición es imposible, dado que la pretensión de repetición

17 Søren Kierkegaard, La repetición, trad. de Demetrio Gutiérrez Rivero, Madrid: Alianza, 2009, p. 188.

18 Ibíd., pp. 27-28. 
se fragua en una dialéctica entre lo acontecido (recuerdo) y la esperanza de que eso reviva la satisfacción del pasado. Es imposible porque la esperanza de repetir no puede reelaborar el pasado ya perdido.

Lo interesante de la reflexión kierkegaardiana no es en sí su conclusión -o al menos no lo es para los fines de este trabajo- sino su análisis existencial de la conducta humana. La pregunta importante que se hace Kierkegaard en el sentido de este trabajo es ¿por qué el ser humano pretende repetir cosas de su pasado y de la vida en sí? Vemos pues aquí completamente un análisis psicológico del comportamiento humano que, como se ha reprochado desde el inicio, es completamente desconocido para la historia de la psicología. ¿Acaso este análisis kierkegaardiano es irrelevante para la historia del pensamiento psicológico? ¿Es acaso que dicha reflexión no aportó nada al análisis de la existencia humana y de la conducta? ¿No puede ser bien esta reflexión un elemento de peso para pensar o repensar las condiciones de posibilidad en las que se fragua la existencia humana y por ello, la estructura de la psique humana?

Desde una perspectiva histórica, evidentemente esta reflexión aporta elementos centrales al entendimiento de la psique y la existencia. De manera contundente, se considera que el concepto de repetición es un antecedente directo del psicoanálisis, en específico, del concepto freudiano de «compulsión a la repetición» (pulsión de muerte). En vida, Freud fue cuestionado (por Otto Rank) del parentesco que tenía su obra con la de Schopenhauer y Nietzsche, a lo que él reaccionó mencionando que básicamente no los conocía, aunque encontraba cierta cercanía con su obra $^{19}$. A Freud nunca se le cuestionó acerca de Kierkegaard y del concepto kierkegaardiano de repetición, sin embargo, puede ser, como pasó con otros autores, que Freud lo haya leído y nunca le haya dado el crédito que merecía en su obra. Evidentemente es una polémica que nunca se podrá resolver, pues no hay una sola evidencia que demuestre que Freud tuvo un acercamiento al pensador danés, hasta ese momento, un tanto desconocido. ¿Por qué si hay cierta cercanía y parentesco en el concepto de repetición entre Freud y Kierkegaard, Freud sí aparece y Kierkegaard no, en la historia de la psicología?

19 Textualmente Freud menciona: "En una época posterior, me rehusé el elevado goce de las obras de Nietzsche con esta motivación consciente: no quise que representaciónexpectativa de ninguna clase viniese a estorbarme en la elaboración de las impresiones psicoanalíticas". Cfr. Sigmund Freud, Contribución a la bistoria del movimiento psicoanalitico, Obras completas, vol. XIV, trad. de Luis Echeverri, Buenos Aires: Amorrortu, 1992, p. 15. 
La reflexión que hace Kierkegaard de la repetición se entrelaza con las teorizaciones de Freud, lo cual no subsume a dicha reflexión debido a que la teorización freudiana va a ir en otro carril, a saber, que la repetición es una compulsión, o de un regreso a una inorganicidad anímica, o una compulsión gozosa de repetir un acontecimiento en donde hubo una satisfacción inconsciente en oposición a la aversión consciente de repetir dicho acontecimiento. En Freud, la repetición se aleja de la dimensión existencial, mientras que, en Kierkegaard, la repetición es existencial. Como se ha mencionado en el apartado anterior, Lacan va a ser el psicoanalista que recuperará la teorización kierkegaardiana de la repetición en su dimensión existencial, mostrando los límites de ésta con relación al psicoanálisis propiamente.

\section{B. Angustia y desesperación}

Siguiendo el sentido que guía a este trabajo, desde una perspectiva histórica, Kierkegaard sería el fundador de la psicología existencial ${ }^{20}$. Como se pudo apreciar en el apartado anterior, la reflexión kierkegaardiana de la repetición aporta elementos para analizar el alma y conducta de los individuos; ahora, presentaré lo correspondiente a la angustia y la desesperación, lo cual forma parte del núcleo de la reflexión existencial kierkegaardiana madura.

Es bueno mencionar que la angustia, para Kierkegaard (con el seudónimo de Vigilius Haufniensis), es una angustia ante la presencia de Dios y del pecado. El ser humano siente angustia con respecto a la elección de pecar y no pecar, ante el bien y mal de corte judeocristiano. Desde aquí, si algo se le puede reprochar a Kierkegaard en cuanto a la fundamentación de su psicología existencial, es que ésta tiene una estructura intencional cristiana. Ahora bien, la teorización kierkegaardiana sobre la angustia se puede trasladar en sí, al tema de la libertad y elección existenciales

20 Es una idea debatible, pues si se considera que Kierkegaard no es el padre de la filosofía existencial moderna, no se podría sostener a su vez, que sea el padre de la psicología existencial, pues intrínsecamente -desde una posición general del concepto de psicología y no desde puramente el concepto de psicología moderna- en ciertos sistemas filosóficos se podría deducir un tipo de psicología. Habrá quien argumente que puede deducirse una psicología existencial en San Agustín o Pascal, pero según lo que se sostiene aquí, formalmente, Kierkegaard sería el primer pensador que aporta rigurosa y extensamente un sistema psicológico de corte existencial. He aquí donde estriba el valor y relevancia de Kierkegaard en la historia de la psicología. Aunado a esto, este trabajo sería una demostración de dicho valor y relevancia. 
como hizo Sartre ${ }^{21}$, lo que daría oportunidad de hablar con toda libertad de una psicología y psicoterapia existenciales. Entonces, el valor de la conceptualización de la angustia en Kierkegaard va en el sentido de mostrar que ésta se sufre y padece antes de ser psicológica como tal (sería ontológica, no psicopatológica). Por dicha razón, es que Rollo May y los demás psicoterapeutas existenciales, demostrarán que dicha dimensión existencial era totalmente desconocida para mediados del siglo XX; ni el psicoanálisis freudiano, ni el conductismo, habían hecho un análisis e incorporación de esta dimensión del ser humano.

Así bien, la angustia planteada por Kierkegaard se diferencia del miedo o del terror, mostrando que en éstos hay algo determinado, mientras que la angustia es "la realidad de la libertad como posibilidad antes de la posibilidad" 22 . En efecto, la angustia surge como indeterminación frente al infinito de posibilidades a escoger; la angustia sería parte de la estructura de la existencia, es decir, sería ontológica, porque acontece ante la posibilidad de elegir antes de elegir como tal. De ahí que Kierkegaard sostenga que la angustia interiorice al sujeto, es decir, que, ante la angustia, los seres humanos comienzan a tener una conducta patológica de aislamiento. Kierkegaard menciona:

En la intimidad de cada hombre siempre existe la angustia de estar solo en el mundo, olvidado y descuidado por Dios, en este inmenso gobierno de millones y millones. Uno sofoca esa angustia con la visión de tantos hombres como nos rodean, vinculados a nosotros por la naturaleza o por amistad; pero la angustia persiste y uno no osa pensar en lo que experimentaría si todo eso le fuera arrebatado ${ }^{23}$.

También al respecto, Rodrigo Figueroa Weitzman nos comenta lo siguiente:

El ser humano es lanzado en la angustia casi sin oportunidad de detenerse; pues siendo reflexiva, es paralela a la ruptura del contacto con el mundo. La

21 La fundamentación de una psicología y psicoterapia existenciales fue uno de los intereses de J-P Sartre. Con su trabajo sobre el «psicoanálisis existencial», Sartre intenta retomar el concepto de angustia presentes en la obra de Kierkegaard y Heidegger, y llevarlo a una aplicación psicoterapéutica. Evidentemente la intensión de Sartre es sacar el concepto de angustia kierkegaardiano de su estructura intencional cristiana. Cfr. J-P. Sartre, "El psicoanálisis existencial", en El ser y la nada, trad. de Juan Valmar, Buenos Aires: Losada, 1993.

22 Søren Kierkegaard, El concepto de angustia, trad. de Demetrio Gutiérrez Rivero, Madrid: Alianza, 2016, p. 43.

23 Søren Kierkegaard, Diario intimo, trad. de María Angelica Bosco, Barcelona: Planeta, 1994, p. 252. 
angustia aísla a la persona que la sufre, envolviéndola en una situación de la que puede ser muy difícil salir, como una especie de circulo vicioso. Esta soledad acentúa la misma angustia, ya que la persona se encierra más y más en sí misma, evitando también la relación con otros. Por un pudor muy natural, el angustiado se oculta a los demás, aunque arde en deseo de comunicar su sufrimiento a alguien capaz de comprenderlo. El angustiado quiere y necesita ayuda, pero a veces teme ver su dolor expuesto a un sentimiento ajeno de piedad $^{24}$.

Siguiendo lo expuesto, la angustia descrita por Kierkegaard es una angustia que acontece ante la posibilidad de las posibilidades, ante el pecado. Adán vive la angustia por haber pecado, carga con la culpa del pecado, pero no es una culpa abstracta, es la culpa de haber elegido. La posibilidad de elegir angustia al ser humano, pero también lo angustia decidir como tal, pues al decidir, éste carga con el peso (culpa) de su decisión; la real angustia deviene de la consciencia de saber que esto es así todo el tiempo de vida, es decir, que siempre el ser humano se afrontará a decisiones en las cuales tendrá que hacer una elección. Sería precisamente un continuo devenir de angustia en el cual no hay salida ${ }^{25}$.

Por otra parte, la desesperación en Kierkegaard (con el seudónimo de Anti-Climacus) no es estrictamente lo mismo que la angustia, pero son conceptos que se entrelazan. Kierkegaard va a sostener en su texto sobre La enfermedad mortal que hay tres tipos de desesperación: "el desesperado inconsciente de tener un yo (lo que no es verdadera desesperación); el desesperado que no quiere ser él mismo, y aquel que quiere serlo" ${ }^{26}$. A su vez, va a sostener que la desesperación es la enfermedad mortal. Así como sucede con el concepto de angustia, la desesperación se circunscribe a una estructura intencional cristiana, pues la desesperación es una enfermedad mortal que sólo tiene sentido si se piensa a la vida y la muerte en sentido cristiano. Para Kierkegaard la desesperación existe (cuando se es consciente de que el yo es el espíritu) y eso asume que no hay muerte como tal, o sea, que hay una vida más allá de la muerte física. El desesperado desespera

24 Rodrigo Figueroa, El concepto de angustia en Søren Kierkegaard, Santiago: Universidad Andrés Bello, p. 55.

25 De aquí que muchos psicoterapeutas existenciales o terapeutas filosóficos hablen del acompañamiento emocional-existencial en la toma de decisiones. El trabajo terapéutico en este sentido parece indicar poner en contexto al consultante sobre sus posibilidades de elección y trazar junto al terapeuta, un mapa de elección, con lo cual no estoy muy de acuerdo.

26 Søren Kierkegaard, La enfermedad mortal, trad. de Demetrio Gutiérrez Rivero, Madrid: Trotta, 2008, p. 33. 
por querer morir, una especie de rebelión en contra de Dios y el espíritu que vive dentro del hombre (en el yo). En consecuencia, también está la desesperación del que no quiere morir, o sea, ser él mismo en cuanto a su infinitud espiritual.

La teorización de la desesperación en Kierkegaard, siguiendo la línea de investigación de este trabajo, es una teorización que aporta elementos para entender la formación existencial del yo y su funcionalidad. De nuevo, las semejanzas con Freud son interesantes, aunque distantes. En Kierkegaard, podríamos hablar de una escisión del yo: un yo que desea ser lo que es, y un yo, que no desea ser él mismo, una especie de autoafirmación y negación subjetiva, entendidas éstas en un marco existencial cristiano (el espíritu como posibilidad infinita y la temporalidad humana como posibilidad finita). En la primera, sobre un yo que quiere ser él mismo, Kierkegaard estaría pensando a un yo que se acepta y vive acorde de la infinitud del espíritu (da el salto a la fe). En la segunda, estaría pensando en un yo que no desea ser él mismo con relación a la infinitud del espíritu (un yo narcisista). La teorización yoica de Kierkegaard es dialéctica y parece mostrar claramente el malestar existencial del sujeto que posee un yo.

Si bien es evidente que el yo kierkegaardiano es un yo cristiano y suscrito a un sistema cristiano, la teorización existencial del malestar yoico sin duda tiene relevancia psicológica y clínica. Si se piensa a un yo desesperado por ser él mismo, éste se pierde en el infinito de su propia imaginación causándole desesperación por el aterrador peso de ese infinito; este yo se encierra en sí mismo imaginándose de manera delirante, como lo dirá metafóricamente Kierkegaard "como un cazador de mariposas que, en el ansia de cazar la mariposa, se pierde en la selva y olvida el camino de vuelta" ${ }^{27}$. Ahora, si se piensa a un yo desesperado por no ser él mismo, se ve a un yo que cae en la finitud de las determinaciones: legales, laborales, económicas, sociales, etc., y que paulatinamente, por la falta de libertad, pierde su imaginación y espiritualidad. Por lo tanto, aquí se puede esbozar una teoría psicopatológica existencial, así como una teoría del yo.

Según lo que he podido mostrar en este apartado, Kierkegaard tuvo un sólido pensamiento psicológico que lo llevó a develar aspectos centrales de la existencia humana. La repetición, la angustia y la desesperación son sólo algunos conceptos de la obra de Kierkegaard que nos ayudan a sostener la tesis de que, en efecto, Kierkegaard es un relevante e interesante pensador del alma y comportamiento humanos. La exclusión de Kierkegaard de la

27 Søren Kierkegaard, Mi punto de vista, trad. de José Miguel Velloso, Buenos Aires: Aguilar Ediciones, 1972, p. 54. 
historia de la psicología es patente, su relevancia innegable y su relación con doctrinas o pensadores de la psicología es imprescindible. Sería bueno leer trabajos donde se valore y reconozca la importancia que tiene el gran pensador danés, en la historia general de la psicología.

\section{Bibliografía}

\section{Obras de Kierkegaard}

Kierkegaard, Søren, Diario intimo, trad. de María Angelica Bosco, Barcelona: Planeta, 1994.

_El concepto de angustia, trad. de Demetrio Gutiérrez Rivero, Madrid: Alianza, 2016.

_ Johannes Climacus o el dudar de todas las cosas, trad. de Patricia Carina Dip, Buenos Aires: Gorla, 2007.

_L La enfermedad mortal, trad. de Demetrio Gutiérrez Rivero, Madrid: Trotta, 2008 .

—_L L repetición, trad. de Demetrio Gutiérrez Rivero, Madrid: Alianza, 2009.

_Los primeros diarios. 1834-1835. Vol. I, trad. de María José Binetti Milanesi, México: Universidad Iberoamericana, 2011.

— Mi punto de vista, trad. de José Miguel Velloso, Buenos Aires: Aguilar Ediciones, 1972.

Otras obras consultadas

Brennan, James, Historia y sistemas de la psicología, trad. de José Francisco Dávila Martínez, México: Pearson, 1999.

Brentano, Franz, Psychology from an Empirical Standpoint, London: Routledge, 1995.

Chirinos, María, Intencionalidad y verdad en el juicio. Una propuesta de Brentano, Pamplona: EUNSA, 1994.

Dilthey, Wilhem, Introducción a las ciencias del espiritu, trad. de Eugenio Imaz, México: F.C.E., 1978.

Figueroa, Rodrigo, El concepto de angustia en Søren Kierkegaard, Santiago: Universidad Andrés Bello, 1998.

Freud, Sigmund, Contribución a la bistoria del movimiento psicoanalítico, Obras completas, vol. XIV, trad. de Luis Echeverri, Buenos Aires: Amorrortu, 1992. 
Greenwood, John, Historia de la psicología: un enfoque conceptual, México: McGraw Hill, 2011.

Halbfass, Wilhelm, India y Europa. Ejercicio de entendimiento filosófico, trad. de Óscar Figueroa, México: F.C.E., 2013.

Hothersall, David, Historia de la psicología, México: McGraw Hill, 1997.

Koch, Sigmund \& Leary, David, (ed.) A Century of Psychology as Science, Washington: APA, 2002.

Lacan, Jacques, Seminario XI. Los cuatro conceptos fundamentales del psicoanálisis, trad. de Rithee Cevasco y Vicente Mira Pascual, Buenos Aires: Paidós, 1993.

"El seminario de la carta robada", trad. de Tomás Segovia, en Escritos I, México: Siglo XXI, 1984.

Leahey, Thomas Hardy, Historia de la psicología, trad. de María de Ancos Rivera, Madrid: Pearson, 2005.

May, Rollo, Angel, Ernest \& Ellenberger, Henri, Existence: A New Dimension in Psychiatry and Psychology, Nueva York: Basic Books, 1958.

Nussbaum, Martha, Terapia del deseo, trad. de Miguel Candel, Buenos Aires: Paidós, 2005.

Onfray, Michel, Las sabidurías de la antigüedad: Contrabistoria de la filosofía I, trad. de Marco Aurelio Galmarini, Barcelona: Anagrama, 2008.

Sartre, J-P. "El psicoanálisis existencial”, trad. de Juan Valmar, en El ser y la nada, Buenos Aires: Losada, 1993.

Smith, Samuel, Ideas of the Great Psychologists, New york: Barnes \& Noble, 1983.

Tortosa, Francisco y Civera, Cristina, Historia de la psicología, México: McGraw Hill, 2006.

Yalom, Irving, Psicoterapia existencial, Barcelona: Herder, 2010. 